UDC 791:165:159.9

Yervand RUMYAN

\title{
THE EFFECT OF FILM FRAME SERIES ON VIEWER'S REFLECTIVE PROCESSES (IN THE CROSSROAD OF ART, EPISTEMOLOGY AND PSYCHOLOGY)
}

\begin{abstract}
What kind of a toolkit should be used and how in order to have an impact on the viewer's reflective processes as well as a guide such processes through a film? The author of this article explicates the idea that editing arrangement of shots (frames) series is essential in this aspect. He believes that the full effect and precision of what you want to say is conditioned by the meaningful structure of the series of shots (frames). The latter is achieved as a result of well-thought-out editing. The analysis, hypotheses, and statements presented in the article are subject to further detailed study, particularly from the perspective of general psychology and epistemology. However, it is beyond any doubt that specific succession of shots is forming a contextual and implicative information environment enabling to guide the audience's perception process, thus affecting a person's contemplation processes and emotional state.
\end{abstract}

Keywords: reflection processes, series of shots, editing structure, film effect, the meaningful structure of shot series, editing, perception process.

"If we can awaken the audience's feelings, make them comprehend the idea; then I think that in the future, we will be able to control the reflection process of the audience. This will be one of the greatest achievements of cinematography of the future" (Eisenstein, 2002, p. 34). Sergei Eisenstein said this still years ago when the filmmaking was just beginning to evolve. But the master's prediction was long-standing.

It is one thing to have an influence on the thoughts of the audience and a different thing to guide the process of their thinking activity. One way or another, each film has a certain effect on the audience's psychological activity. But it is different when the filmmaker guides the viewer not only in the process of comprehending the film but also during the meaning processing of perceptions using a particular toolkit - in this case, through a specific sequence of shots. As a result, the viewer is able to perceive and feel exactly what was planned by the author.

If we presume that shots are different senses and their entirety affects a person's getting full perception, then a proper understanding of those perceptions would be comprehension, i.e. meaningful perception. Therefore, seeing shots of the film, the viewer perceives them as separate fragments beginning to combine with each other and as a result getting the complete perception. In this process, the role of the audi- 
ence's thinking processes is essential as the whole analysis of perceptions is based on it.

By saying reflection process, we should understand an abstract logical action that allows the person to combine direct perceptions with the information stored in the memory and get a new result through analysis (Nalchajyan, 1997, p. 259). Without this quality, the viewer would not be able to even understand the general idea of the film developed with the simplest structure of shots. Given the fact that the general analysis of perceptions is made through contemplation, we can assume that guiding the contemplation processes of the viewer will make it possible to manage the development of film perception process.

We find that corroboration of the following concepts is important:

- Shot - a combination of image and sound;

- Editing - intellectual and technical process determining the meaningful structure of a series of shots in the film.

By saying film, we should understand a specific, meaningful structure of shots enabling the viewer to understand this or that idea, feel strained or relaxed, express happy or sad emotions, feel and perceive, imagine and think. The shot structure is a specific "skeleton" containing shots that are interlinked and following each other and leading to the general idea. Removing even one of the ten succeeding shots that contain a general idea can change the whole idea. It is also possible to remove several of them from the series and keep the general idea. However, the shots become powerful and influential when presented as a whole since part of the whole might become senseless.

"An important part of the film, which is essential in making a psychological influence on the viewer is the editing structure of shot series"
(Yanovskiy, 2014, p. 78). Cinematography, as art that combines image and sound and talks through shots, uses editing as a primary tool for structuring the shot series. The series of shots is a system that guides the process of film perception meaning that the viewer has the ability to see and perceive the content placed in the shot series. Based on such perceptions, the viewer makes the general analysis through the recollection of transmitted shots. Editing enables to structure of the shot series in a way that limits not only the entire film perception process but also guides the course of psychological processes generated as a result of the viewer's perceptions.

The possibility of generating different sensations in the viewer's psychology through shot structure was proved still in the initial stage of cinematography. In 1917, Russian film director Lev Kuleshov conducted an experiment that showed the diversity of messages as a result of combining the shots and the differences in perception. This experiment is known as "The Kuleshov Effect". The experiment proved the hypothesis that the same shot can be interpreted differently due to the content of the next shot. In other words, as a result of interaction between two shots, new content is generated that is not separately reflected in either the first or the second shot (Sokolov, 2005, p. 14-15). Later, Sergei Eisenstein furthered the theory of his teacher, "interaction between two shots results in generating a completely new idea based on their meaningful content they bear" (Sokolov, 2005, p. 16). Then he develops the hypothesis referring also to its psychological significance. "The facial expression on the screen is always relative. It depends on what comes next. If we show a smiling face followed by a close-up of a child, you will always say that it is an amiable man or a kind 
woman who are full of paternal or maternal feelings. But if we show the same smiling face followed by a murder scene, the expression of that face will acquire touches of sadism" (Eisenstein, 2002, p. 33). Approaches of experts mastering film language show the flexibility of editing; i.e. shot assembly. Hence, throughthe synthesis of shots, it is possible to not only get new content but also transfer different psychological signals generating different emotions in the viewer. Years later, Artavazd Peleshyan came to the following conviction. "I realized that I am not interested in the interaction between two shots being next to each other regardless of their being combinations or intermissions. I did not combine; I did not merge shot with a shot, but rather I "split", placed them, threw them into space" (Peleshyan, 1988). "Distance Montage": This is how the famous Armenian documentary filmmaker Artavazd Peleshyan titled the rationale of shot sequence authored by him. Peleshyan's films contain numerous psychological effects that transmit the ambience contained in the shots to the viewer and draw inside the screen, making him/her part of the film process. This process is not always at the conscious level during the perception by the viewer, and we can say that such films are mostly perceived at the subconscious level. This means that if the viewer does not perceive the meaning content of the shot series structure at the conscious level, then he/she automatically or subconsciously perceives the whole atmosphere and influence contained in that structure. "The whole is more than the sum of the parts", this famous statement is supported by professor of London College University, Beau Lotto, who states that the viewer sees only 10 per cent of the images through eyes, while the rest is seen by the brain (Florea, 2016, p. 261). Many studies have resulted in a very interesting and important argument: if the full effect of editing structure of film shot series was not perceived by the viewer at the conscious level, it might be perceived subconsciously. "The speed we detect the images during the watching process allows us to maximum perceive only at the unconscious level. It is impossible to focus on the whole visual information that is simultaneously displayed on the screen. We have to always ignore some of what we have seen to focus on the other part. But what we do not see consciously we still see unconsciously. This is an instinctive process that happens to everyone without realizing" (Korbut, 2005). This is the general impact of the film; the viewer receives and perceives many emotions-impulses even when it is not always happening at a conscious level, and the meaningful processing is made througha comprehensive analysis of emotions and perceptions. "The impact on sensory organs is more in the cinema than in the literature; the film directly talks to the unconscious" (Korbut, 2005). The overwhelming majority of perceived impressions do not disappear from our mental world; it remains deep in the memory. This huge mass of our experience not only characterizes our personality but also has a profound impact on today's thoughts and emotions, as well as foresight of the future (Nalchajyan, 1997, p. 95). By studying the so-said "subconscious perception" we can see that the information acquired in everyday life of a person is not entirely at the conscious level, that is, the information received, which in essence has been memorized, is not always available for reproduction. As a result, the previously obtained information is possible to use instinctively only in specific situations. The information acquired is not lost; rather than kept if not at the conscious level, then possibly in the subconscious. On the same principle, the Ameri- 
can businessman James Waikerie decided to carry out an experiment based on an in-depth study of the so-called person's "subconscious perception". With the use of $25^{\text {th }}$ frame, he was able to convey short, but effective information to the viewer (Florea, 2016, p. 261). Consequently, we can assume that film perception is in progress at all levels - conscious, unconscious and subconscious, while the particularity of this process is conditioned by a certain structure of shots. Talking about the influence of films we should note down one more important feature - the greatest manifestation of the film effect on a person's emotional field is associated with the phenomenon of "catharsis". Certainly, the living-through process is related to the viewer's encounter of a favourite character in film, nevertheless, in order to convey the entire spectrum of characters' emotions to the viewer it is necessary to have such an assembly of shots that would lead the viewer to certain emotional state causing the viewer to live through and resulting in catharsis.

All this is a consequence of the fact that shot series can direct the whole process of the viewer's perception. In the "Psychology of Film Perception" research thesis the Soviet psychologist Nikolay Zhinkin trying to explore the viewer's perception mechanism, i.e. how the film is perceived, claims that "unlike other forms of art, a film is a form of art that causes directional perceptions" (Zhinkin, 1971). K. P. Korbut (2005) also expressed a similar opinion characterizing the effects of film as follows: "Unlike painting, when we can scrutinize the details and analyze their influence, the film images are presented only briefly like in the dream process; we are not able to stop the film (except when we are making mental analysis) and focus on a particular image". Consequently, we perceive what is presented to us and perceiving more than that is ba- sically limited by the film and the main reason for that is directing the viewer's perception.

The structure of the shot series limits the perception process focusing the viewer's mental activity on the film and affecting a range of mental processes - attention, senses, perceptions, memory, imagination and thinking. The film is a specific sign system encoded through a series of shots and intended to be decoded during the perception process. All this is done through the deliberate rendering of shot series. In other words, a specific combination of shots structured through editing logics already predetermines the viewer's possible perception. "Film is a continuous link between the shots that do not have gaps, breaks and distances. That is why a film can rule not only the initial perception but also the meaningful processing of information" (Zhinkin, 1971). Looking for the probable psychological impact in the editing structure of shots we come to the conclusion that all psychic processes taking place during the viewer's perception are conditioned by the transmitted shots with their effect being determined by a certain meaningful arrangement and presentation as a whole. Consequently, if the editing structure of shot series makes it possible to affect several psychological processes of the viewer, then the probability of affecting the thinking process is also logical.

In order to direct the viewer's thinking process, first of all, you need to move it. When Jesus Christ, God's only begotten Son wanted to transmit a new commandment to his disciples, he was doing it through parables. What was the purpose of communicating it in that manner? The point is that conceptual thinking is not typical to everyone, and not everyone understands it. While imaginary thinking is comprehensible and understandable to everyone. After all, he could 
convey the word in a clearer manner simplifying the process of perception and understanding. The idea was to wake up the interlocutor's thinking: when we hear new information, let's say something simple that does not require long mental work to comprehend it; but when a parable is told that generally requires interpretation the interlocutor's mind initiates cognitive processes in an attempt to satisfy his/her cognitive needs. Thinking is placed in action, i.e. reasoning, combining these or other thoughts, recalling the information previously available in the memory and making general analysis, thus trying to satisfy the cognitive needs of the person.

It should be also noted that the correct and full understanding of the transferred information depends on individual abilities. This is also true for a film, where the editing structure of shot series is moving according to the above-mentioned principle, i.e. such structures of shot series that would not only stimulate viewer's thinking processes but also affect them.

The Bible is a book having, at first glance, simple content, but simultaneously, it has many layers that very often are not perceived and interpreted unequivocally. It is an inexhaustible source of diverse interpretations and analysis. Unlike all other books, the Bible has a peculiarity: The Old and New Testaments talk about the same topic and in order to understand what is being said in one of these two books it is necessary to study half of the other book in details. The importance of completeness is also expressed in the film. For example, in A. Peleshian's film "We" the close-up sight of a girl looking on the camera lens is repeated in a timespace; each time when this frame appears on the screen it makes the viewer mentally go back to the previous scene and find the link between these two scenes. The frames can be distributed in space and time, thus expressing their main message only in the complete structure. As a result, the viewer needs to collect the shots in different parts of the film and make a general analysis. But if the concentration of resolute attention and memory is required from the viewer for combining different fragments read in the book then in the film it's different. The film director uses all audiovisual tools to force the viewer to recall all the perceived frames and combine them with the frames being transmitted and as a result, make a general analysis. Thus, through a certain meaningful structure of shots, it is possible to guide the viewer by affecting his/her thinking processes.

\section{REFERENCES}

Eisenstein, S., (2002). Psikhoologicheskie voprosy iskusstva (Psychological Questions of Art, in Russian). Moscow: Smysl.

Florea, M., (2016). History of the $25^{\text {th }}$ Frame. The Subliminal Message. Communication and Globalization, 6(3), 261266. Retrieved March 1, 2019, from http://www.ijcr.eu/articole/330 07\%2 0Maria\%20FLOREA.pdf.

Korbut, K. P., (2005). Psikhoanaliz o kino i kino o psikhoanalize (Psychoanalysis about Cinema and Cinema about Psychoanalysis, in Russian). Zhurnal Prakticheskoi Psikhologii i Psikhoanaliza, 2. Retrieved February 3, 2019, from:

http://psyjournal.ru/articles/psihoanaliz -o-kino-i-kino-o-psihoanalize

Nalchajyan, A. A. (1997). Hogebanut'yan himunqner (Basics of Psychology, in Armenian). Yerevan: Hogeban. 
Peleshyan, A. A. (1988). Moe kino (My Film, in Russian). Retrieved March 5, 201, from: http://www.kinozapiski.ru/ru/ print/sendvalues/853/.

Sokolov, A. G. (2005). Montazh. Televidenie, kino, video (Editing. Television, Cinema, Video, in Russian), Vol. I. Moscow: Uchebnik.

Yanovskiy, M. (2014). Psikhologicheskoe vozdeistvie montazhnikh postroenii $v \mathrm{ki}$ novideoryade (Psychological Impact of Film Shot Series in Film and Video
Sequence, in Russian). Penzenskii psikhologicheskii vestnik, 2(3), 58-83. Retrieved January 8, 2019 from: https://cyberleninka.ru/article/v/psihol ogicheskoe-vozdeystvie-montazhnyhpostroeniy-v-kinovideoryade.

Zhinkin, N. I. (1971). Psikhologiya kinovospriyatiya (Psychology of Film Perception, in Russian). Kinematograf segodnya (Cinematograph Today, in Russian), 214-254. Moscow: Iskusstvo. 